\title{
XI. On some chemical effects produced by platinum
}

\section{Dr. C.F. Schœnbein}

To cite this article: Dr. C.F. Schœnbein (1846) XI. On some chemical effects produced by platinum , Philosophical Magazine Series 3, 29:191, 40-47, DOI: 10.1080/14786444608562599

To link to this article: http://dx.doi.org/10.1080/14786444608562599

曲 Published online: 30 Apr 2009.

Submit your article to this journal ๘

Џ Article views: 2

Q View related articles $\sqsubset$ 
learnt the art of cross-examining nature, and the latter has not. The difference between the man who has a genius for inductive philosophy, and the man who has none, is-that the one has a sagacity, which the other wants, in discovering media of proof, and driving his interrogatories to a point. Little or nothing depends on the multiplication of experiments, everything on the selection; and the only guides to selection are, first, a quick analogical perception-and, secondly, a just and sound appreciation-of the causes of phænomena.

\section{Errata in Vol. XxviII.}

Page 489, line 24, for 1764 read 1664 .

... 492, ... 5 , for " consumes it " read "it is consumed."

... 492, ... 36, for 1764 read 1664 .

... 495, ... 43, for 1764 read 1664 .

... $514, \ldots 5$,... for "duodecimo volume, of scarce a hundred pages" read " treatise of scarce seventy pages."

XI. On some Chemical Effects produced by Platinum. By Dr. C. F. Schonbein*.

SOME time ago I published an account of a series of expe5 riments made with the resin of guaiacum, from which it appeared that the substance named is instantly rendered blue, not only by chlorine and nitrous acid, but also by bromine, iodine, ozone, and a number of metallic peroxides.

Free oxygen, be it pure or mixed with nitrogen, hydrogen, and carbonic acid gas, does not act in the dark upon that resinous matter, and comparatively very little when exposed to the action of solar light. From these facts, it becomes manifest that oxygen must have assurned a peculiar condition of chemical excitement before it is capable of causing the reaction mentioned. The beautiful experiments both of Davy and Dobereiner have demonstrated that platinum has the power to occasion the oxidation of a number of substances under circumstances in which that chemical action would not take place without the agency of that metal. The blue coloration which the resin of guaiacum assumes under certain circumstances is most likely dependent upon a partial oxidation of that substance, and the latter being so very sensible to oxygen, that happens to be chemically excited, it could easily be conjectured that platinum in a state of minute mechanical division put in contact with the resinous substance mentioned, might cause the oxidation of the latter in the

- Communicated by the Chemical Society ; having been read December 1,1845 . 
same manner as that metal occasions the oxidation of hydrogen, xther and alcohol. The facts $I$ am going to state will show that the correctness of this conjecture is fully borne out by experiment.

Newly-prepared spongy platinum being placed upon a piece of filtering paper that had previously been drenched with an alcoholic solution of resin of guaiacum, caused rather rapidly the appearance of blue spots at the place where the metal had been in contact with the resinous solution. My experiments have further shown that that reaction takes place the more rapidly and intensely the more divided the platinum happens to be of which we make use in the experiment described. What is called Platinum Black acts therefore more energetically than spongy platinum does. From the facts stated, it appears that platinum in a state of minute mechanical division conducts itself towards resin of guaiacum like the simple halogenous bodies, ozone and a number of metallic peroxides. These facts demonstrate also that the coloration of the resinous matter being caused by platinum, belongs to that series of phænomena which takes place when that metal is put in contact with a mixture of oxygen and hydrogen, oxygen and vapour of æether, \&c.

In the paper above alluded to, I have pointed out the remarkable coincidence that all the substances having the power of rendering blue the resin of guaiacum possess also the property of decomposing iodide of potassium, transforming the yellow prussiate of potash into the red one, and I add, decomposing sulphuretted and ioduretted hydrogen, transforming sulphurous acid into sulphuric acid, and destroying organic colouring matters. We shall presently see that platinum in a state of minute mechanical division has the same power.

If a crystal of pure iodide of potassium be put upon a piece of filtering paper that has previously been moistened with distilled water and spongy platinum be placed upon that paper, the spot touched by the metal assumes rather rapidly a brownish red colour. This coloration does not result from free iodine, but is most likely due to a compound consisting of periodide of platinum and iodide of potassium. That conjecture is founded upon the following facts. If a solution of iodide of potassium is put in contact with spongy platinum, or platinum black, the former assumes a perceptibly red colour, which disappears on heating the solution to its boiling-point. Now it is well known that the compound before mentioned yields with water a red solution, the colour of which is destroyed by heat. Neither the red solution nor the brownish-red spots before 
mentioned are able to render blue paste of starch, another proof that there is no free iodine in the case. The reaction described is most likely brought about in the following manner: the chemically excited oxygen surrounding the spongy platinum decomposes iodide of potassium, a peculiar peroxide of potassium being formed and iodine eliminated. The latter in its nascent state combines with platinum to produce the periodide of that metal, which itself unites with iodide of potassium into that compound, yielding with water a red solution. It is worthy of remark, that a solution of iodide of potassium having been treated with spongy platinum, enjoys the property of colouring blue the paste of starch on being mixed with dilute and pure sulphuric acid. The snme reaction is exhibited by the same solution after it has been treated either with ozone or peroxide of lead. If some drops of a weak, $i$. e. colourless solution of the yellow prussiate of potash, be added to platinum black, that solution assumes a perceptibly yellow colour, and yields with a solution of chemically pure sulphate of protoxide of iron a blue precipitate.

From these facts, it seems to follow that platinum has the power to transform the yellow prussiate into the red one. Some years ago I tried to show that spongy platinum being placed in an atmosphere of sulphuretted hydrogen, loses its property of acting upon detonating gas, on account of a film of sulphur being deposited on the surface of the metal. Such being the case, it would follow that spongy platinum has the property to decompose sulphuretted hydrogen.

Colourless hydriodic acid, on being mixed up with some platinum black, assumes a brownish yellow colour, which reaction indicates an elimination of iodine.

Several chemists, particularly Dobereiner, Phillips, and Brunner, have ascertained that spongy platinum produces sulphuric acid on being placed in contact with moist oxygen and sulphurous acid, and there is no doubt that platinum black put into sulphurous acid gives rise to the formation of sulphuric acid. Moist filtering paper being coloured by a solution of indigo and put in contact with spongy platinum for about twenty-four hours, appears entirely bleached at those spots which had touched the metal. I have repeated this experiment more than thirty times, and always with the same result. This remarkable fact proves that platinum in a state of minute mechanical division, has the power of destroying organic colouring matters, and acts as a real bleaching agent. Before passing to other subjects, I must not omit to mention a circumstance which seems to me meriting some attention. It is a curious fact, which has not escaped the 
notice of chemists, that in more than one case platinum acts exactly like common electricity, both of them determining at the common temperature, for instance, the oxidation of free hydrogen. Now it being well known that nitric acid is formed if electrical sparks are made to pass through moist air, it seemed to me within the reach of possibility, that the same acid might be produced by platinum, if that metal in a state of minute mechanical division were placed in contact with moist atmospheric air. With the view of ascertaining the correctness of that conjecture, I put a piece of moist litmus paper in close contact either with spongy platinum, or with platinum black. In some cases part of the paper exhibited a slight reddish coloration, part of it proved to be entirely bleached, or nearly so. I must, however, not omit to state, that in the great majority of my experiments I obtained bleaching effects only, and no reddening of the litmus paper whatever. I am unable to account for the difference of the results mentioned. Was the reddening of the litmus paper caused by some traces of nitric acid formed under the circumstances indicated? I am not prepared at all to answer that question. If nitric acid should however happen to be produced under the circumstances mentioned, it would be a fact, in my opinion, not very difficult to be accounted for. In whatever state the oxygen surrounding platinum may be, certain it is that that state is such as to render oxygen very apt to combine at the common temperature with a number of oxidable substances that would not be oxidized by common oxygen without the presence of platinum. The formation of nitric acid taking place under the circumstances mentioned, would indeed be a fact very similar to the combustion of detonating gas caused by platinum. I repeat, however, that I consider the generation of nitric acid brought about by the agency of platinum, as far from being established by decisive facts.

The voltaic character of bodies being so intimately connected with their chemical nature, that in most if not in all cases we may infer the one from the other, the fact I am going to state merits our attention. Chlorine, bromine, iodine, ozone, and a number of metallic peroxides, enjoy considerable electro-motive powers, which are of such a kind as to render those bodies what is commonly called electro-negative. Hence it comes that a piece of metal being covered with any one of the bodies named, bears to another common piece of the same metal the same voltaic relation as copper does to zinc. According to the experiments of De la Rive and some other philosophers, platinum foil being covered with some spongy platinum, is negative to common platinum plate, a 
fact which proves that in a voltaic point of view there exists a great analogy between the simple halogenous bodies, ozone and metallic peroxides on one side, and spongy platinum on the other.

After having stated a number of facts which demonstrate the highly oxidizing powers of platinum, we ask in what manner does that metal exalt the chemical activity of oxygen? This question has occupied many philosophers, and been answered in very different ways. Faraday and Dobereiner ascribe to platinum the power of condensing oxygen so much as to deprive that element of its gaseous condition, and think that condensed state to be the true cause of the oxidizing powers of platinum. Others (De la Rive and Gmelin) presume that oxygen is capable of chemically uniting with that metal, and with those philosophers it is the oxide of platinum that occasions the oxidation of hydrogen, \&c. Berzelius holds the opinion that the oxidations caused by platinum are catalytical phænomena, $i$. $e$. effects produced by some unknown force being innate to that metal and exalting the chemical attractive powers of oxygen.

It is not my intention to enter into a discussion of those opinions; I shall confine myself to a few general remarks upon that interesting subject. As the common oxides of platinum are not acted upon (at the common temperature) by free hydrogen, as platinum foil or wire, that causes at a moderate temperature the combustion of detonating gas, exhibits a perfect metallic surface, while the thinnest film of an oxide diminishes or destroys the lustre of any metal, and as platinum is a body that has a very weak affinity for oxygen, I think that that metal is not capable of combining directly with the oxygen of the air, and that De la Rive's view of the subject is erroneous. But how is it with Faraday's and Dœbereiner's theory of the matter in question? It seems indeed to be the true one. Satisfactory however as that hypothesis may appear, it is nevertheless possible that the oxidizing action of platinum may depend upon a cause different from what the philosophers mentioned consider as such.

We know that phosphorus being put in contact with moist atmospheric air gives rise to the formation of a highly oxidizing agent, which, as it has been shown elsewhere, seems to be a peculiar compound of water and oxygen, and enjoys the power of oxidizing a great number of substances at the common temperature. Now if phosphorus enjoys that property, it seems possible that some other substances, for instance platinum and iridium, may do the same. In other terms, it appears possible that platinum has the power to en- 
gender out of free oxygen and water a highly oxidizing peroxide, which surrounding that metal empowers the latter to cause all the oxidations above mentioned. In comparing the chemical properties of platinum, when minutely divided, with those of ozone, we cannot help being struck by their great similarity, as will appear from the following statements :-

1. Both substances possess a negative electro-motive power.

2. Both of them destroy organic colouring matters.

3. Both of them render the resin of guaiacum blue.

4. Both of them decompose iodide of potassium.

5. Both of them change the yellow prussiate of potash into the red one.

6. Both of them transform sulphurous acid into sulphuric acid.

7. Both of them decompose oxalic and formic acids.

8. Both of them act in a similar way upon æether and alcohol.

Great as the similarity of properties may be, it does not fol. low that platinum owes its oxidizing powers to a film of peroxide of hydrogen being formed round the metal by a catalytical action of the latter. I have not yet succeeded in producing, by the means of spongy platinum and moist air, an atmosphere exbibiting the peculiar electrical smell, bleaching power and oxidizing properties which belong to ozone. Considering the great volatility of the last-named substance, we should suppose that it ought to disperse into the surrounding medium as soon as formed; or should ozone be retained by platinum in a way similar to that in which we think oxygen is attached to and condensed around that metal? Supposing oxygen to be an odoriferous substance, it is manifest that the oxygen actually condensed by platinum could not affect the olfactory nerves.

Another objection might be raised to the conjecture, that it is a film of peroxide of hydrogen, to which platinum owes its oxidizing powers, from the fact that Thenard's oxygenized water is really decomposed by platinum. Considering however that ozone is in some respects strikingly different from Thenard's compound, having for instance a peculiar odour, being insoluble in water, transforming both metallic silver and its basic oxide into a peroxide, it appears possible that ozone is capable of existing in the closest contact with platinum without suffering decomposition. I am not aware of spongy platinum or platinum black having been treated with anhydrous oxygen, and I do not know whether it has been ascertained if the latter is absorbed as easily by that metal as moist oxygen. It is equally unknown to me whether platinum, after being placed in dry oxygen or air, exhibits 
the same properties as platinum after being exposed for some time to the same gases when moist. If the oxidizing powers of platinum should depend upon a film of peroxide of hydrogen attached to that metal, it is obvious that spongy platinum, freed from its adhering water and placed within completely dry oxygen, could not assume oxidizing properties. Supposing however that spongy platinum acquires oxidizing powers under the circumstances mentioned, we may nevertheless imagine that those powers depend upon a film of peroxide of hydrogen surrounding that metal. De la Rive's and Marignac's experiments have shown that oxygen obtained from fused chlorate of potash, on being exposed to the action of electrical sparks, yields perceptible quantities of ozone. Now, taking that odoriferous substance for a peroxide of hydrogen, we must admit that even that oxygen, which is considered as absolutely anhydrous, still contains traces of aqueous vaponr. Taking for granted the humidity of what is called dry oxygen, we may easily conceive how platinum brought into an anhydrous mixture of oxygen and hydrogen could cause the combustion of the latter. Out of some oxygen and the traces of water still contained in what is considered anhydrous detonating gas, a film of peroxide of hydrogen would be formed around the spongy platinum; that peroxide, in the very moment of its being engendered, would oxidize a neighbouring portion of free hydrogen. The heat resulting from that oxidation would determine another portion of hydrogen to unite with oxygen. The heat proceeding from that chemical union would occasion the combustion of an additional portion of hydrogen, and so on until the whole of the detonating gas should be consumed. The minute quantity of the peroxide of hydrogen attached to the spongy platinum would act like a small common or electrical spark, which, as we well know, is capable of setting the largest volume of detonating gas on fire. Electrical sparks acting upon a mixture of oxygen and hydrogen, exactly in the same way as spongy platinum does, and it being a well-ascertained fact that ozone makes its appearance on causing common electricity to pass through (moist) oxygen, it is possible that electricity and platinum occasion the oxidation of hydrogen, because both of them are able to produce ozone, and that it is to the agency of that odoriferous substance that we are to ascribe the chemical effect mentioned. That conjecture must become still more plansible, if we take into account the fact that spongy platinum acts in a variety of other cases exactly like ozone. Taking this view of the case, we could not admit that an electrical spark has the power to cause directly the formation 
of water out of detonating gas, but should be obliged to consider the oxidation as occasioned by the ozone being formed under electrical influence out of aqueous vapour and oxygen. In other terms, we are obliged to ascribe the oxidation to the same cause from which we derive the decomposition of iodide of potassium, the transformation of the yellow prussiate of potash into the red one, the destruction of vegetable colouring matters, the turning blue of the resin of guaiacum, the transformation of the protoxide of lead into the peroxide, \&c., brought about by the electrical brush. Now, as it can hardly be doubted any longer that the chemical effects just stated are due to ozone produced by electricity, the conjecture, according to which free hydrogen may also be oxidized by electrical ozone, seems to be very probable. Indeed, if potassium, the hydrogen of colouring matters, the oxide of lead, \&c., are oxidized by the oxygen of electrical ozone, why should free hydrogen make an exception to the rule?

But however that may be, the subject under discussion seems to be interesting, and I add, still obscure enough to offer an inducement to chemists to apply themselves to its elucidation by further investigations. The matter merits our attention the more that it bears so close a relation to that series of chemical phænomena which are called catalytical actions, and which certainly belong to the most enigmatical facts of our science.

\section{Proceedings of Learned Societies.} ROYAL SOCIETY.

[Continued from vol, xxviii. p. 416.]

Feb. 12, "A PRACTICAL Extension of the Application of the 1846. A Law of Mortality announced by B. Gompertz, Esq., in the Philosophical Transactions for 1823." By A. M. Drach, Esq. Communicated by B. Gompertz, Esq., F.R.S.

In endeavouring to verify the theoretical law of mortality, announced by Mr. Gompertz, by means of constants derived from the results of the English census of 1841, which are contained in the sixth Annual Report of the Registrar-General, and which furnish an extended basis for computation, the author found the accordance between the two to be so remarkably close as to justify the assumption that Mr. Gompertz's formula expresses the true law of the decrement of human life. The paper is occupied with the analytical details of this investigation.

"On Spontaneous Nitrification." By C. F. Schœnbein, Professor of Chemistry in the University of Bâle. Communicated by Michael Faraday, Esq., D.C.L., F.R.S., \&c.

From various facts adduced by the author, he is led to the con- 